\title{
Doenças de ovinos diagnosticadas no Laboratório de Anatomia Patológica Animal da Universidade Federal de Mato Grosso do Sul $(1996-2010)^{1}$
}

\author{
Thiago L. Almeida ${ }^{2 *}$, Karine B. Brum ${ }^{3}$, Ricardo A.A. Lemos ${ }^{4}$, Cassia R.B. Leal ${ }^{4}$ \\ e Fernando A. Borges ${ }^{4}$
}

\begin{abstract}
Almeida T.L., Brum K.B., Lemos R.A.A., Leal C.R.B. \& Borges F.A. 2013. [Sheep diseases diagnosed at the Laboratory of Animal Pathology, Federal University of Mato Grosso do Sul, Brazil (1996-2010).] Doenças de ovinos diagnosticadas no Laboratório de Anatomia Patológica Animal da Universidade Federal de Mato Grosso do Sul (1996-2010). Pesquisa Veterinária Brasileira 33(1):21-29. Departamento de Medicina Veterinária, Faculdade de Medicina Veterinária e Zootecnia, Universidade Federal de Mato Grosso do Sul, Av. Senador Filinto Müller 2443, Vila Ipiranga, Cx. Postal 549, Campo Grande, MS 79070-900, Brazil. E-mail: thiagoalmeida2@hotmail.com

Sheep farming has increased significantly in Brazil during the last decades. Concurrently, research groups and diagnostic laboratories compile data and perform retrospective studies to provide important insight for professionals. A prevalence study from January 1996 to December 2010 was carried out in the archives of Laboratório de Anatomia Patológica Animal (LAP), Universidade Federal de Mato Grosso do Sul (UFMS). Laboratório de Bacteriologia, UFMS, and Setor de Patologia Veterinária at Universidade Federal do Rio Grande do Sul helped on the diagnostic of pulmonary mannheimiosis and scrapie respectively. The reports for sheep were reviewed and grouped into conclusive and inconclusive ones. The conclusive cases were classified according to the etiology of the disease. In the period, 331 exams (3.97\%) were done. Sixty-four experimental cases and materials from other states or countries (19.3\%) were excluded. Remaining cases (267), eighty-seven (32.6\%) were inconclusive and $180(67.4 \%)$ were considered conclusive reports, were classified according to the etiology: 60 (33.3\%) infectious and parasitary diseases; $45(25 \%)$ were poisonings and toxi-infections; 41 (22.8\%) were summarized as "injuries without apparent cause"; 22 $(12.2 \%)$ cases of metabolic and nutritional diseases; 10 (5.6\%) were classified as "other disorders" and $2(1.1 \%)$ case of neoplasms. Haemonchosis, fibrinonecrotic or fibrinopurulent pleuropneumonia, bronchopneumonia and pneumonia, poisonings by Brachiaria spp. and copper poisoning were the most prevalent diseases in sheep. Two cases of scrapie have been diagnosed in this period.
\end{abstract}

INDEX TERMS: Pathology, photosensitization, pneumonia, prion disease, transmissible spongiform encephalopathy, worms, sheep.

\footnotetext{
${ }^{1}$ Recebido em 13 de março de 2012.

Aceito para publicação em 18 de outubro de 2012.

Parte da Dissertação de Mestrado do primeiro autor

${ }^{2}$ Programa de Pós-Graduação em Ciência Animal, Faculdade de Medicina Veterinária e Zootecnia (Famez), Universidade Federal de Mato Grosso do Sul (UFMS), Av. Filinto Müller 2443, Vila Ipiranga, Cx. Postal 549, Campo Grande, MS 79080-900, Brasil. *Autor para correspondência: thiagoalmeida2@hotmail.com

${ }^{3}$ Centro de Ciências Biológicas e da Saúde (CCBS), UFMS, Cidade Universitária s/n, Cx. Postal 549, Campo Grande, MS. E-mail: karine.brum@ufms.br

${ }^{4}$ Famez-UFMS, Campo Grande, MS 79070-900, Brasil. E-mails: ricardo. lemos@ufms.br, cassia.leal@ufms.br, fernando.borges@ufms.br
}

RESUMO.- Nas últimas décadas a pecuária ovina cresceu significativamente no Brasil. Concomitantemente, grupos de pesquisas e laboratórios de diagnósticos realizam estudos retrospectivos com a finalidade de fornecer subsídios técnico-científicos para os médicos veterinários. Desta forma, realizou-se um estudo de prevalência nos arquivos do Laboratório de Anatomia Patológica Animal (LAP) da Universidade Federal de Mato Grosso do Sul (UFMS) no período de Janeiro de 1996 a Dezembro de 2010. O Laboratório de Bacteriologia da UFMS e o Setor de Patologia Veterinária da Universidade Federal do Rio Grande do Sul forneceram 
apoio diagnóstico nos casos de mannheimiose pulmonar e scrapie, respectivamente. Os laudos da espécie ovina foram revisados e agrupados em conclusivos e inconclusivos, dos quais foram excluídos os casos experimentais e de outros estados e países. Os casos conclusivos foram classificados de acordo com a etiologia da doença. Os exames da espécie ovina somaram 331 laudos $(3,97 \%)$ de um total de 8.333 casos diagnosticados no período. Destes, foram excluídos sessenta e quatro $(19,3 \%)$ casos experimentais e materiais oriundos de outros estados ou países. Dos 267 casos remanescentes, $87(32,6 \%)$ foram inconclusivos e $180(67,4 \%)$ considerados conclusivos, sendo 60 (33,3\%) doenças infecciosas e parasitárias; 45 (25\%) intoxicações e toxi-infecções; 41 (22,8\%) "lesões sem causa definida"; 22 (12,2\%) doenças metabólicas e nutricionais; $10(5,6 \%)$ foram classificadas como "outros distúrbios" e 2 (1,1\%) neoplasmas. A hemoncose, intoxicação por Brachiaria spp., pleuropneumonias, broncopneumonias, pneumonias fibrinonecrosante ou fibrinossupurativa sem causa definida e a intoxicação por cobre foram as doenças mais prevalentes no período estudado. Dois casos de scrapie foram diagnosticados no período.

TERMOS DE INDEXAÇÃO: Pneumonia, hemoncose, intoxicação por Brachiaria spp., intoxicação por cobre, scrapie, ovinos.

\section{INTRODUÇÃO}

A ovinocultura têm se destacado dentro da produção animal nos últimos anos no Brasil. Os produtores rurais vêm buscando formas alternativas de diversificação de suas atividades pecuárias a fim de incrementar a rentabilidade da empresa rural (Viana \& Silveira 2008).

0 censo do Instituto Brasileiro de Geografia e Estatística (IBGE) no ano de 2010 apresenta um rebanho nacional ovino com 17.380.581 cabeças. A região Centro-Oeste detém um rebanho total de 1.268 .175 ovinos, sendo o terceiro maior produtor nacional, aquém apenas da região Nordeste (9.857.754 cabeças) e região Sul (4.886.541 cabeças). 0 estado de Mato Grosso assume a liderança no número de animais na região Centro-Oeste com 549.484 cabeças, seguido pelo estado de Mato Grosso do Sul com 497.102 cabeças (IBGE 2010).

Com o incremento do rebanho nacional e regional, o nível alto de monitoração sanitária visa promover a profilaxia e o controle das enfermidades para que, dessa forma, minimizem-se as perdas econômicas causadas por enfermidades que acometem o rebanho nacional. Em convergência e contrapartida com essa realidade, o Ministério da Agricultura, Pecuária e Abastecimento (MAPA) aprovou o regulamento técnico do Programa Nacional de Sanidade dos Caprinos e Ovinos (PNSCO) no ano de 2004.

O PNSCO tem por objetivos a vigilância epidemiológica e sanitária para as doenças de caprinos e ovinos no Brasil (Brasil 2009). Neste contexto, os estudos epidemiológicos e clínico-patológicos são importantes no reconhecimento das enfermidades e determinação de suas prevalências nas diferentes regiões do país.

Diante dessa expansão da atividade e a diversidade dos diagnósticos das doenças de ovinos nas diferentes regiões e estados brasileiros, alguns grupos de pesquisadores e la- boratórios de diagnósticos estão compilando os dados obtidos nas últimas décadas e realizando estudos retrospectivos. Estes estudos fornecem subsídios técnico-científicos e informações regionais das enfermidades com maior prevalência no Brasil. Desta forma, os profissionais têm acesso a dados regionalizados que podem auxiliar no diagnóstico clínico e laboratorial das enfermidades de ovinos (Nóbrega Júnior et al. 2005, Guedes et al. 2007, Macêdo et al. 2008, Rissi et al. 2010).

Devido à escassez de informações referentes ao rebanho sul mato-grossense, realizou-se um estudo de prevalência a fim de relatar a epidemiologia, os sinais clínicos e os achados anatomopatológicos das principais enfermidades que acometeram a espécie ovina nos últimos quatorze anos.

\section{MATERIAL E MÉTODOS}

Realizou-se estudo de prevalência nos arquivos do Laboratório de Anatomia Patológica (LAP) da Faculdade de Medicina Veterinária e Zootecnia (Famez), Universidade Federal de Mato Grosso do Sul (UFMS), utilizando os laudos de necropsia e exames histopatológicos da espécie ovina emitidos entre os meses de janeiro de 1996 e dezembro de 2010. Os dados foram obtidos em necropsias realizadas por médicos veterinários do LAP ou por profissionais autônomos que os enviaram para o exame histopatológico. Os casos experimentais e materiais de outro estado ou país foram excluídos desse estudo. Os dados epidemiológicos, clínicos e patológicos foram coletados e classificados como conclusivos ou inconclusivos. Por sua vez, os diagnósticos conclusivos foram agrupados de acordo com a metodologia adaptada de Rissi et al. (2010) em: 1) intoxicações e toxi-infecções; 2) doenças infecciosas e parasitárias; 3) doenças metabólicas e nutricionais; 4) neoplasmas; 5) "lesões sem causa definida" e 6) "outros distúrbios", para aqueles que não se enquadravam nos grupos citados anteriormente. o Laboratório de Bacteriologia da Famez realizou o isolamento e identificação do agente etiológico no caso de mannheimiose pulmonar e o Setor de Patologia Veterinária da Universidade Federal do Rio Grande do Sul realizou o diagnóstico imuno-histoquímico dos dois casos de scrapie.

\section{RESULTADOS}

Durante o período pesquisado (1996-2010) foram realizados 8.333 exames histopatológicos e/ou necropsias em diversas espécies de animais no LAP. Dentre eles, 331 laudos eram da espécie ovina, perfazendo $3,97 \%$ do total de exames. Foram excluídos 64 (19,3\%) casos experimentais e exames histopatológicos oriundos de outro estado ou país. Obteve-se, então, 267 casos, dos quais, oitenta e sete foram considerados inconclusivos $(32,6 \%)$ pela falta de colheita e submissão de materiais ou a presença de tecidos autolisados que impossibilitaram o diagnóstico. Dos 180 (67,4\%) laudos conclusivos, $60(33,3 \%)$ eram doenças infecciosas e parasitárias; 45 (25\%) eram intoxicações e toxi-infecções; $41(22,8 \%)$ foram sumarizadas como "lesões sem causa definida"; 22 (12,2\%) eram doenças metabólicas e nutricionais; $10(5,6 \%)$ foram classificadas como "outros distúrbios"; 2 (1,1\%) eram neoplasmas. A lista das doenças, os dados epidemiológicos e as alterações clínico-patológicas estão representados nos Quadros 1, 2 e 3, respectivamente. 0 número de casos recebidos no LAP durante os quatorze anos pesquisados está representado na Figura 1. 
Quadro 1. Doenças de ovinos diagnosticadas no Laboratório de Anatomia Patológica, Faculdade de Medicina Veterinária e Zootecnia, Universidade Federal de Mato Grosso do Sul (1996 a 2010)

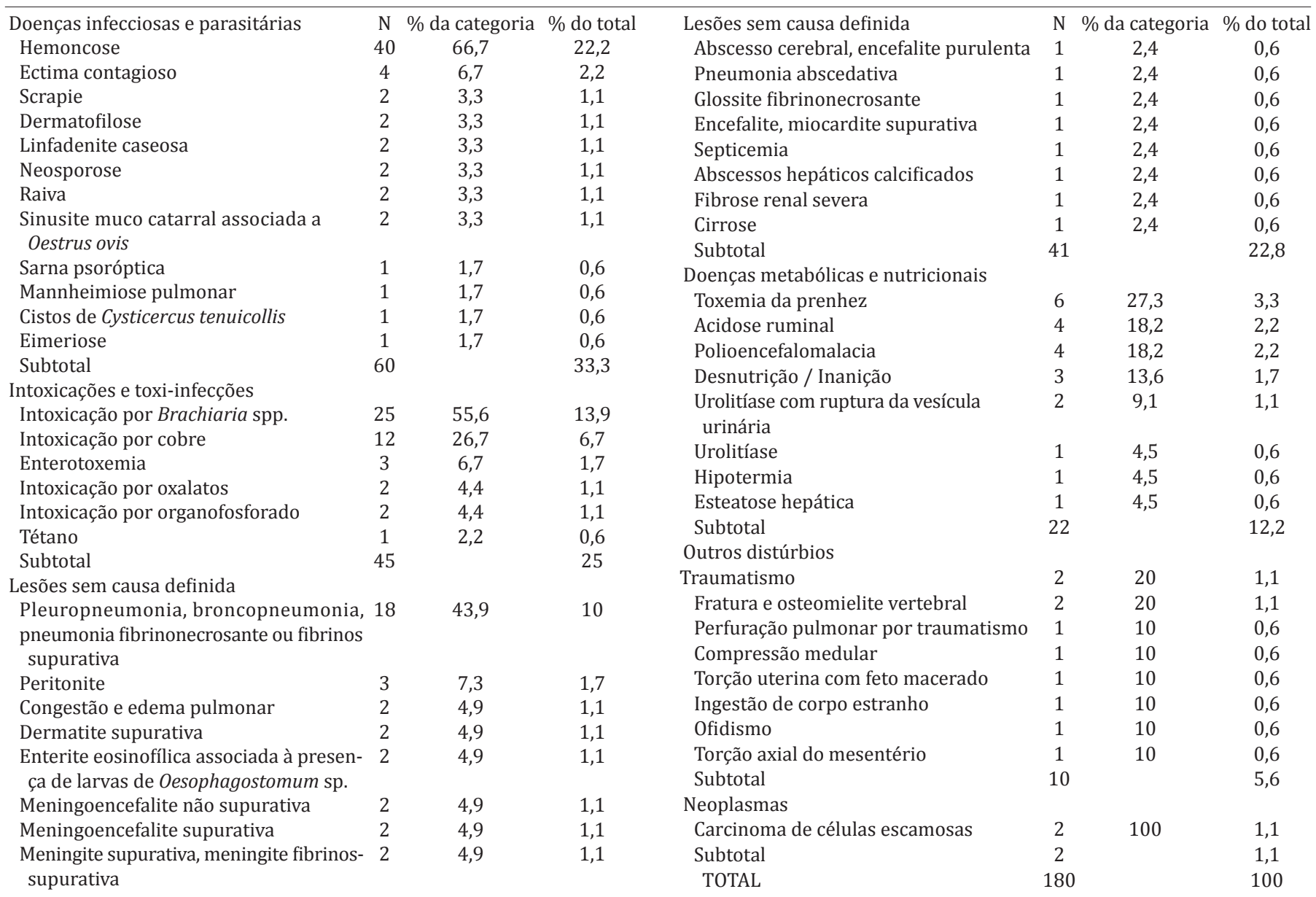

Quadro 2. Epidemiologia das principais doenças de ovinos diagnosticadas no Laboratório de Anatomia Patológica, Faculdade de Medicina Veterinária e Zootecnia, Universidade Federal de Mato Grosso do Sul (1996 a 2010)

\begin{tabular}{|c|c|c|c|c|c|}
\hline Doença & Época de & Idade $^{\mathrm{a}}$ & & Sexo & \\
\hline & ocorrência & (média) & & & $\mathrm{NI}^{\mathrm{d}}$ \\
\hline Intoxicação por Brachiaria spp. & Primavera e verãc & $3-40(12)$ & 11 & 10 & 4 \\
\hline Intoxicação por cobre & Não sazonal & $1-24(10)$ & 7 & 4 & 1 \\
\hline Hemoncose & Não sazonal & $3-72(25)$ & 18 & 21 & 1 \\
\hline Scrapie & Outono e inverno & $3(3)$ & 1 & 1 & 0 \\
\hline Toxemia da prenhez & $\begin{array}{c}\text { Outono, inverno } \\
\text { e verão }\end{array}$ & $12-60(36)$ & 0 & 6 & 0 \\
\hline Acidose ruminal & Outono e inverno & $7-18(15)$ & 0 & 4 & 0 \\
\hline Polioencefalomalacia & Outono e inverno & $2-6(3)$ & 2 & 2 & 0 \\
\hline $\begin{array}{l}\text { Pleuropneumonia, broncopneu- } \\
\text { monia, pneumonia fibrinone- } \\
\text { crosante ou fibrinossupurativa } \\
\text { sem causa definida }\end{array}$ & Não sazonal & $<1-96(22)$ & e 6 & 9 & 3 \\
\hline
\end{tabular}

${ }^{\mathrm{a}}$ Em meses, ${ }^{\mathrm{b}}$ machos, ${ }^{\mathrm{c}}$ fêmeas, ${ }^{\mathrm{d}}$ não informado, ${ }^{\mathrm{e}}$ três ovinos tinham menos de 15 dias.

\section{DISCUSSÃO}

O número de casos de ovinos recebidos pelo LAP teve um incremento nos últimos 14 anos (Fig.1). Esse evento pode ser explicado por dois fatores: o aumento no rebanho estadual e expansão da ovinocultura e a busca por assistência técnica por parte dos ovinocultores.
A hemoncose foi a doença mais prevalente no estado durante o período estudado. 0 Haemonchus contortus, agente causal da doença, é importante parasita gastrointestinal hematófago que provoca perdas produtivas no rebanho, com o decréscimo na produção de carne e lã (Urquhart et al. 1998, Ruas \& Berne 2007). A alta prevalência destaca sua importância dentre os parasitas gastrointestinais, também observadas em outros estados, como no Rio Grande do Sul (Rissi et al. 2010) e na região Sudeste (Amarante et al. 2004). Os principais sinais clínicos não divergiram da literatura, sendo que a palidez de mucosas, o emagrecimento progressivo, edema submandibular e hidrotórax e/ou ascite, provocados pelo baixo volume globular e hipoproteinemia estavam presentes em todos os casos estudados (Ruas \& Berne 2007).

Numerosos exemplares de Haemonchus contortus visualizados na mucosa abomasal confirmaram o diagnóstico em 24 dos 36 casos. A ausência da visualização do parasita nos demais casos pode ser explicada pelo avançado grau de autólise do animal (Radostists et al. 2007) ou devido a não inspeção do conteúdo abomasal durante a necropsia. A contagem de ovos do tipo Strongylida por gramas de fezes dos animais (OPG) foi realizada em cinco casos, apresentando valores entre 5.500 e 15.200 . Os animais eram adultos, com exceção de um caso (seis meses) e sem raça definida.

Valores acima de 600 OPG indicam um elevado número de parasitas nos animais, considerando-se uma infecção 
Quadro 3. Características clínico-patológicas e dados complementares das principais doenças de ovinos diagnosticadas no Laboratório de Anatomia Patológica, Faculdade de Medicina Veterinária e Zootecnia, Universidade Federal de Mato Grosso do Sul (1996 a 2010)

Doença Sinais clínicos Achados de necropsia Alterações histopatológicas $\quad$ Dados complementares

Intoxicação por Bra- Secreção nasal e ocular, opacida- Carcaça pálida a ictérica, fíga- Tumefação e vacuolização do ci- Animais jovens. Surtos duranchiaria spp. de corneana, cegueira, ressecamen- do com coloração amarelada, toplasma dos hepatócitos. Infil- te todos os meses do ano com to do focinho, apatia, anorexia, ic- consistência firme, padrão lo- trado mononuclear ao redor dos sazonalidade marcante na priterícia, edema de face, formação de bular evidenciado, bordas ar- canalículos biliares, luz dos duc- mavera e verão.

crostas ao redor do olho e orelha. redondadas e com impressão tos biliares e na região peripordas costelas em sua superfí cie. tal. Proliferação de células do ducVesícula biliar distendida e re- to biliar e de tecido conjuntivo fipleta de líquido. Rins com co- broso. Retenção biliar na luz dos loração acastanhada. ductos biliares e nos sinusóides hepáticos. Presença de cristais opticamente ativos ou imagens negativas de cristais em nove casos e de macrófagos com citoplasma espumosos ("foam cells") em cinco casos.

Intoxicação por cobre Mucosas oculares e orais ictéricas, Fígado friável com coloração a- Necrose individual de hepatóci- Animais com históricos de aliapatia, prostração, urina com colo- laranjada. Vesícula urinária re- tos da região centrolobular, tume- mentação com alto teor de coração escura, dificuldade locomo- pleta de urina com coloração fação e vacuolização de hepató- bre e submetidos a situações tora, decúbito e opistótono. escura. Rins aumentados de vo- citos nas regiões mediozonais e, de estresse (transporte). Curso lume com áreas hemorrágicas em alguns casos, periportais. Pro- da doença rápido e, muitas vee edematosos. Icterícia gene- liferação de tecido conjuntivo nos zes, ocorre morte sem o apareralizada. espaços porta. Presença de ma- cimento dos sinais clínicos. crófagos com citoplasma abundante preenchidos por pigmento marrom-amarelado. Retenção biliar entre os sinusóides hepáticos, ductos e canalículos biliares. Degeneração e necrose tubular renal com formação de cilindros hialinos.

Hemoncose

Debilidade, apatia, anorexia, ema- Mucosas oculares e orais pá- Degeneração ou necrose de coa- Animais de várias idades. Ogrecimento, palidez de mucosas, lidas, hidropericárdio, ascite gulação hepatocelular centrolo- corrência durante todo o ano edema submandibular, dispnéia, e presença de exemplares de bular. e sem predileção sexual. pelos eriçados e decúbito esternal. Haemonchus sp. no abomaso em vinte e quatro casos.

Scrapie Emagrecimento progressivo, pru- Sem alterações macroscópicas. Neurônios e prolongamentos neu- Animais adultos da raça Hamrido intenso com movimentos contra objetos e perda de lã. ronais com vacuolização citoplas- pshire Down e Suffolk. mática, dando aspecto de esponja ao corte histológico. À imunohistoquímica anti-príon observou-se imunomarcação positiva intensa em corpos neuronais, axônios e placas perivasculares.

Toxemia da prenhez

Animais em estado avançado de Hidrotórax e hidropericárdio. Degeneração hepática com vacuo- Animais em estado final de gesgestação, taquipnéia, dispnéia, in- Equimoses no omento maior lização no citoplasma de hepa- tação. Ocasionalmente algumas coordenação motora, convulsões, e musculatura da cavidade ab- tócitos. Degeneração e necrose de fêmeas com gestação gemelar. prostração e decúbito. dominal. Fígado esbranquiça- células epiteliais tubulares renais. do com regiões multifocais a- Em um caso observou-se áreas vermelhadas, friável, padrão de congestão e necrose no útero. lobular evidenciado e bordos arredondados (hepatomegalia). Presença de fetos em estágio avançado de gestação, sendo dois casos com gestação gemelar.

Acidose ruminal Hipertermia, dificuldade locomo- Hiperemia ruminal. tora, mucosas cianóticas, edemana face, sialorréia intensa, anorexia.
Vacuolização, tumefação e pre- Sazonalidade marcante no pesença de alguns focos de necro- ríodo da seca (outono e inverse de coagulação das células da no). Histórico de confinamenmucosa ruminal. Presença de in- to e fornecimento de alimenfiltrado neutrocitário na mucosa tos ricos em carboidratos. ruminal em um caso. 
Quadro 3. (Cont.) Características clínico-patológicas e dados complementares das principais doenças de ovinos diagnosticadas no Laboratório de Anatomia Patológica, Faculdade de Medicina Veterinária e Zootecnia, Universidade Federal de Mato Grosso do Sul (1996 a 2010)

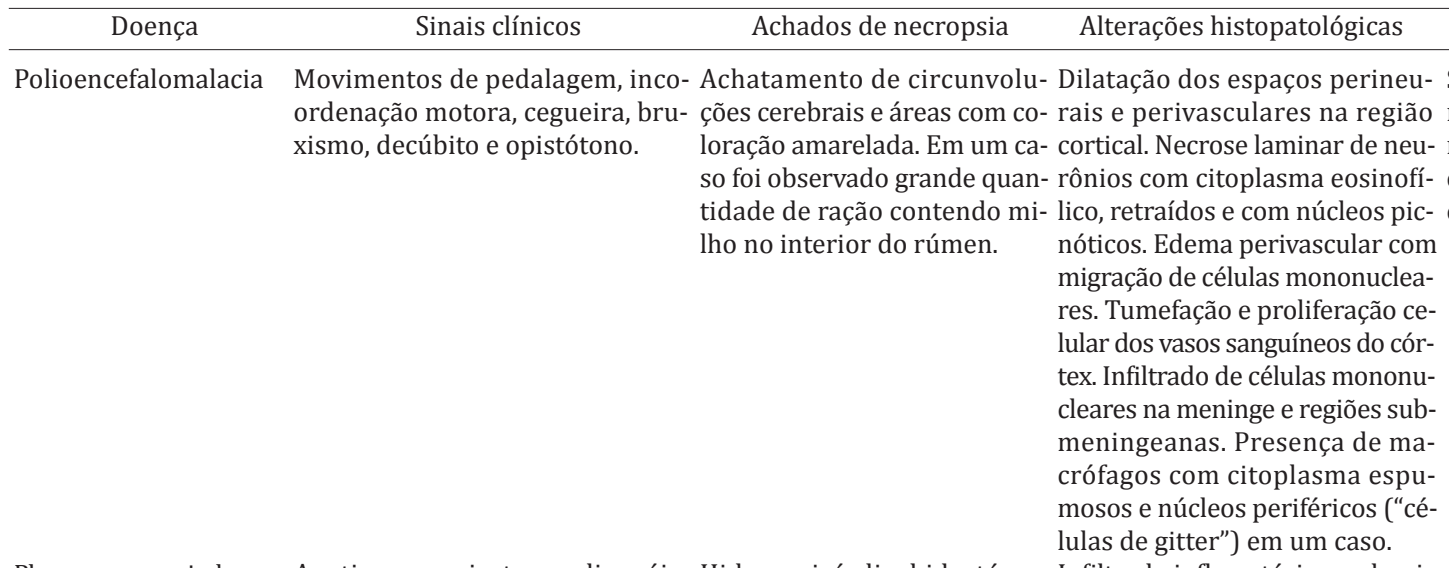

Pleuropneumonia, bron- Apatia, anorexia, tosse, dispnéia, Hidropericárdio, hidrotórax, Infiltrado inflamatório predomi- Animais de várias idades. Ocorcopneumonia, pneumo- incoordenação motora, mucosas pulmão com áreas enegreci- nantemente neutrofílico assu- rência durante todo o ano. Fania fibrinonecrosante ou pálidas, hipertermia, secreção na das, aderência pulmonar crâ- mindo a forma de "grão de areia". tores imunossupressores como fibrinossupurativa sem sal purulenta e decúbito esternal. nio-ventral com deposição de Presença de estruturas fortemen- verminose, transporte e poucausa definida fibrina. Hepatização pulmonar. te basofílicas (colônias bacteria- ca idade foram relatados em Petéquias ou sufusões pleurais. nas). Congestão e edema inters- alguns casos. 0 caso de ManPresença de espuma na tra- ticial ou na luz alveolar, com áreas nheimiose pulmonar apresenquéia. de deposição de fibrina. Focos de tou características clínico-panecrose de coagulação, áreas he- tológicas semelhantes a pleumorrágicas e formação de trom- ropneumonia fibrinonecrosanbos. Proliferação de pneu- móci- te sem causa definida. tos tipo II.

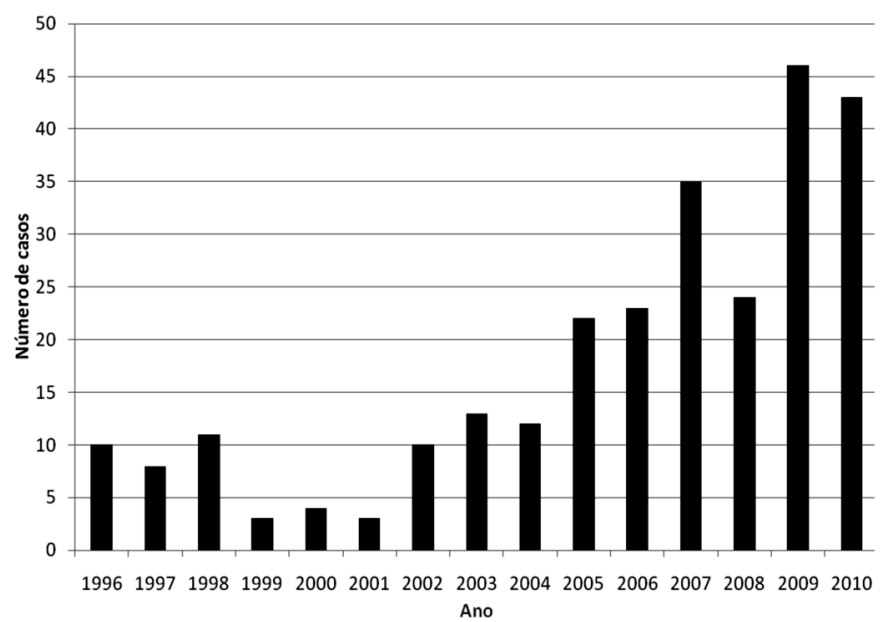

Fig.1. Número de casos de ovinos recebidos no Laboratório de Anatomia Patológica, Faculdade de Medicina Veterinária e Zootecnia, Universidade Federal de Mato Grosso do Sul entre 1996 e 2010.

mista de nematóides (Ruas \& Berne 2007), porém, a avaliação clínica e a utilização de outros meios diagnósticos, como a técnica de Famacha ${ }^{\circledR}$, são importantes no diagnóstico da hemoncose e no controle e tratamento com anti-helmínticos.

Sczesny-Moraes et al. (2010) testaram alguns princípios ativos anti-helmínticos disponíveis em formulações comerciais, como o albendazole, closantel, ivermectina, levamisole, moxidectina, triclorfon e a associação de albendazole, ivermectina e levamisole. Dentre esses, a ivermectina e o albendazole isolados não apresentaram eficácia na redução de ovos após o tratamento, demonstrando resistência de $100 \%$ do $H$. contortus a esses dois princípios ativos testados no Mato Grosso do Sul. Estudo semelhante foi conduzido por Cunha-Filho et al. (1998) no estado do Paraná, onde foi observada uma resistência acima de $80 \%$ a ivermectina e $100 \%$ ao albendazole.

A utilização errônea ou indiscriminada de anti-helmínticos leva ao desenvolvimento e seleção de cepas resistentes de $H$. contortus as formulações comerciais existentes no mercado, aumentando a incidência da doença. (Sczesny-Moraes et al. 2010). Desta forma, os principais desafios da ovinocultura são o controle e tratamento da hemoncose no Mato Grosso do Sul. A administração de anti-helmínticos em doses corretas e em períodos estratégicos são métodos eficazes para o controle da helmintose no rebanho estadual.

As intoxicações por plantas do gênero Brachiaria spp. têm demonstrado alta ocorrência no estado, ocupando o primeiro lugar no ranking das intoxicações e toxi-infecções deste estudo. As saponinas esteroidais litogênicas, presentes em Brachiaria decumbens, mostram fortes evidências de serem as causadoras de fotossensibilização hepatógena em ovinos no estado de Mato Grosso do Sul (Lemos et al. 1996, 2009, Brum et al. 2007). A média de idade dos animais afetados foi de 12 meses, demonstrando uma maior susceptibilidade em animais jovens em relação aos adultos (Lemos et al. 1996, Riet-Correa \& Méndez 2007, Santos et al. 2008, Castro et al. 2009, Lemos et al. 2009, Mustafa 2009, Albernaz et al. 2010).

Os surtos apresentaram uma sazonalidade marcante no período da primavera e verão, coincidindo com o aumento dos índices pluviométricos (Lemos et al. 2009). Exis- 
tem ainda relatos de surtos durante todo o ano nos estados de Goiás, Minas Gerais e Distrito Federal, porém com uma maior incidência no período seco (Mustafa 2009) ou ainda no final do período chuvoso, entre os meses de abril a junho no estado de Mato Grosso (Mendonça et al. 2008).

No estado de Mato Grosso do Sul, a taxa de morbidade apresentou uma variação de 4,6 a $60 \%$, enquanto a taxa de letalidade foi de $50 \%$ a $100 \%$ (Lemos et al. 2009). Valores semelhantes a esses também foram observados em surtos acompanhados nos estados de Goiás, Minas Gerais e Distrito Federal, onde a taxa de morbidade variou entre $15,4 \%$ e $57,1 \%$, e a taxa de letalidade entre 29,4 e $86,5 \%$ (Mustafa 2009). Essas variações das taxas de morbidade e letalidade acompanhadas nos surtos pelos autores supracitados podem ser explicadas pela alta toxicidade da pastagem ingerida ou pela susceptibilidade de alguns animais à intoxicação, seja pelo primeiro pastejo da planta (animais não adaptados ao consumo) ou por um fator genético (Riet-Correa et al. 2011).

Os ovinos deste estudo apresentaram sinais clínicos compatíveis com a fase aguda ou subaguda e crônica da intoxicação por braquiárias. Na fase aguda os principais sinais clínicos são apatia, anorexia, edema de face e orelha, descarga ocular e nasal e hiperemia conjuntival com desenvolvimento dos sinais clínicos entre 24 e 96 horas. Entretanto, os quadros de icterícia e fotossensibilização podem estar ausentes pelo rápido curso da doença, em virtude da gravidade das lesões hepáticas, e a morte dos animais. Nas manifestações subagudas ou crônicas, o período de latência é de 15 a 45 dias, e, além dos sinais observados na fase aguda, observam-se a fotodermatite, fotofobia com movimentos da cabeça, cegueira, emagrecimento progressivo e icterícia (Lemos et al. 1996, Brum et al. 2007, Mustafa 2009, Riet-Correa et al. 2009, Saturnino et al. 2010, Riet-Correa et al. 2011).

A colangiohepatopatia associada ou não à presença de cristais foi achado frequente nos animais deste estudo, corroborando os achados de lesões histopatológicas observadas em casos espontâneos e trabalhos experimentais (Lemos et al. 1996, Driemeier et al. 1998, Cruz et al. 2001, Brum et al. 2007, Mustafa 2009, Saturnino et al. 2010).

Os casos de pleuropneumonias, broncopneumonias e pneumonias fibrinonecrosante ou fibrinossupurativa sem causa definida podem estar associados à infecção por Mannheimia haemolytica (antiga Pasteurella haemolytica) ou por doenças virais, como a língua azul (Araújo et al. 2009; Antoniassi et al. 2010). Entretanto, os fragmentos coletados durante a necropsia foram apenas conservados em formol, viabilizando somente o exame histopatológico. É importante também priorizar a colheita de materiais para o exame microbiológico nos casos com suspeita de pneumonias bacterianas ou virais. Em apenas um caso foi coletado material para o exame bacteriológico, onde foi isolada e identificada M. haemolytica.

A maioria dos casos de intoxicação por cobre mostrou evidências do curso crônico da doença, caracterizado pelo acúmulo de cobre no organismo (fase subclínica). Posteriormente a liberação do cobre na corrente sanguínea é desencadeada por fatores estressantes, como o transporte dos animais, alteração na dieta e a lactação, provocando um quadro hemolítico, que caracteriza a fase aguda da doença (Rosa \& Gomes 1982, Méndez \& Riet-Correa 2007, Radostits et al. 2007). A intoxicação crônica por cobre pode ser primária, pela ingestão de alimentos contendo altos níveis de cobre, ou secundária pela ingestão de pastagens com quantidades normais de cobre, porém, com baixa concentração de molibdênio (Méndez \& Riet-Correa 2007) ou ainda em decorrência de lesão hepática causada pela ingestão de algumas plantas tóxicas, como Senecio brasiliensis (Ilha et al. 2001) e Crotalaria retusa (Dantas et al. 2004).

0 mecanismo da hemólise ainda não está bem elucidado (Pereira et al. 2009), entretanto, acreditam-se que os efeitos tóxicos do cobre são decorrentes da interação com alguns compostos presentes nas membranas das hemácias levando a formação de agentes oxidantes, além da inibição de enzimas importantes para os eritrócitos, como a glutationa redutase e piruvato quinase, provocando o aumento na formação da metahemoglobina (Jain 1993, Inaba 2000).

Em três casos de intoxicação por cobre foram relatados a aquisição e o transporte dos animais de outros estados, demonstrando intoxicações primárias pelo mineral e o transporte como fator estressante que desencadeou os quadros clínicos (Méndez \& Riet-Correa 2007).

Em um caso de reprodutor mantido em sistema de confinamento foi diagnosticada intoxicação primária por cobre. Neste caso foi realizada a análise da ração e do sal mineralizado, verificando-se níveis excessivos de cobre na alimentação (46,5mg/kg). Relatou-se também que há dois meses outro animal havia morrido após a ingestão desta fonte alimentar na mesma propriedade, apresentando os mesmos sinais clínicos.

A fase aguda hemolítica visualizada pelas mucosas ictéricas, hemoglobinúria e com o auxílio dos dados epidemiológicos confirmaram a doença (Méndez \& Riet-Correa 2007), já que outras enfermidades que apresentam quadro hemolítico em ovinos, como a hemoglobinúria bacilar, ainda não foram relatadas no estado de Mato Grosso do Sul.

Os principais achados macroscópicos foram icterícia, ascite, fígado friável de cor amarelada a alaranjada, rins enegrecidos e edemaciados, e urina de cor vermelho-escuro também foram visualizados em surtos espontâneos (Ribeiro et al. 1995, 2007, Castro et al. 2007, Headley et al. 2008) e em intoxicação experimental por sulfato de cobre (Lemos et al. 1997). Na histopatologia observou-se vacuolização e necrose hepatocelular e fibroplasia. Moderada a severa bilestase e presença de cilíndros hialinos nos rins foi observada em todos os casos deste estudo, corroborando os dados de relatos anteriores (Castro et al. 2007, Headley et al. 2008).

Quatro casos de toxemia da prenhez foram diagnosticados no período. A avaliação física dos animais revelou bom estado nutricional em todas as fêmeas em final de gestação, sendo duas ovelhas com gestação gemelar. Em dois casos as fêmeas sofreram restrição alimentar de dois dias devido ao transporte de outra localidade, fato esse que contribuiu para um baixo suprimento energético para o feto e, consequentemente, a lipólise com a formação de corpos cetôni- 
cos, a fim de equilibrar o déficit energético. Entretanto, essa rota bioquímica leva à esteatose, com formação de microvesículas no citoplasma dos hepatócitos, observados em todos os casos desse estudo (Schild 2007, Cal et al. 2009). As situações de estresse hipoglicêmico, a gestação gemelar e o final do período gestacional são fatores que aumentam a suscetibilidade para a ocorrência da doença (Schild 2007, Schlumbohm \& Harmeyer 2008).

Os casos de acidose ruminal e polioencefalomalacia (PEM) ocorreram no período da seca (outono e inverno), coincidindo com a diminuição na disponibilidade de forragem e o fornecimento de dietas ricas em carboidratos. Quando a mudança na dieta acontece de forma abrupta, sem adaptação prévia dos animais ao novo alimento, ocorre o aumento nas concentrações dos ácidos graxos voláteis, modificação na microbiota ruminal e alta produção de ácido lático, que, por sua vez, é absorvido pelo trato gastrointestinal provocando alteração no equilíbrio hidroeletrolítico (Afonso \& Mendonça 2007). O principal achado macroscópico foi hiperemia ruminal. 0 exame histopatológico revelou vacuolização e tumefação das células da mucosa do rúmen e a presença de alguns focos de necrose de coagulação, descritos também por Silva et al. (2009) em um estudo retrospectivo no estado do Pará.

A PEM foi diagnosticada por meio dos sinais clínico-patológicos. A doença apresenta sinais clínicos neurológicos e está associada ao metabolismo da tiamina em ovinos e, assim como ocorre na acidose ruminal, os animais doentes geralmente têm histórico de confinamento e do fornecimento de quantidades excessivas de grãos sem a prévia adaptação, predispondo à acidose lática que, por sua vez, altera a microbiota ruminal. A falta de bactérias produtoras de tiamina ou a presença de bactérias que hidrolisam a tiamina através da enzima tiaminase levam a um déficit da vitamina no organismo, desencadeando o quadro clínico da doença (Lemos \& Riet-Correa 2007). Entretanto, animais recebendo dietas com altas concentrações de enxofre também desenvolveram os sinais clínicos de PEM no semi-árido paraibano (Lima et al. 2005). Assim, é importante verificar os níveis de enxofre nas misturas minerais ou rações fornecidas aos animais. Com o aumento dos confinamentos de cordeiros existe uma grande probabilidade para a ocorrência de novos casos de acidose ruminal, PEM e enterotoxemia.

Dois casos de scrapie foram diagnosticados em animais das raças Hampshire Down e Suffolk durante o período do estudo, sendo um no ano de 2006 e o outro em 2008. Ambos tinham três anos de idade, sendo um do município de Coxim e o outro de Campo Grande. Nos dois casos, os animais apresentavam os sinais clínicos evidentes da doença, como prurido intenso, perda de lã e alterações locomotoras (Driemeier 2007, Martins 2011). Um dos animais era proveniente do Rio Grande do Sul e foi adquirido em uma feira agropecuária no Mato Grosso do Sul. A histopatologia observou-se vacuolização no citoplasma de neurônios, confirmado pela imuno-histoquímica anti-príon com imunomarcação positiva intensa em corpos neuronais, axônios e placas perivasculares (Martins 2011).
Os dados da Organização Mundial de Saúde Animal (OIE, em inglês) revelam que o último caso de scrapie no país foi diagnosticado no ano de 2009 no estado de São Paulo. A doença é classificada como notificação obrigatória, e o seu controle e vigilância sanitária asseguram as exportações de carne para o mercado internacional, evitando assim, os embargos comerciais impostos pelos países importadores (OIE 2011).

Dos casos inconclusivos $(32,6 \%), 63$ casos $(72,4 \%)$ foram provenientes de análise histológica de fragmentos de tecidos enviados por profissionais que atuam no campo. Esta alta ocorrência pode ser explicada pela falha na inspeção minuciosa do cadáver, identificação e interpretação das lesões macroscópicas e envio de materiais conservados em meios inadequados. 0 restante dos casos $(27,6 \%)$, conforme descritos nos laudos, foram animais necropsiados por profissionais do LAP que, devido ao processo avançado de autólise do material coletado, não foi possível o diagnóstico conclusivo dos casos.

Algumas doenças como a linfadenite caseosa e doenças de pele, como a dermatofilose, são comuns na criação de ovinos e caprinos. 0 baixo número de casos neste estudo pode estar relacionado ao conhecimento dessas doenças pelos produtores rurais e médicos veterinários que atuam no campo e que, muitas vezes, por esse motivo, não encaminham material para o exame histopatológico.

Diante do incremento na exploração pecuária da espécie ovina e a diversidade de diagnósticos, os dados de estudos retrospectivos das doenças serão importantes ferramentas de consulta para os profissionais que trabalham na ovinocultura no estado, fornecendo subsídios técnico-científicos para o reconhecimento, a prevenção e o controle das enfermidades do rebanho estadual.

Agradecimentos.- Aos técnicos, docentes e pós-graduandos do Laboratório de Anatomia Patológica (LAP) da Faculdade de Medicina Veterinária e Zootecnia (Famez-UFMS). Aos médicos veterinários autônomos pelo importante papel no envio das amostras ao LAP.

\section{REFERÊNCIAS}

Afonso J.A.B. \& Mendonça C.L. 2007. Acidose láctica ruminal, p.313-319. In: Riet-Correa F., Schild A.L., Lemos R.A.A. \& Borges J.R.J. (Eds), Doenças de Ruminantes e Equídeos. Vol.2. Pallotti, Santa Maria, RS.

Albernaz T.T., Silveira J.A.S., Silva N.S., Oliveira C.H.S., Reis A.S.B., Oliveira C.M.C., Duarte M.D. \& Barbosa Neto J.D. 2010. Fotossensibilização em ovinos associada à ingestão de Brachiaria brizantha no Pará. Pesq. Vet. Bras. 30(9):741-748.

Amarante A.F.T., Bricarello P.A., Rocha R.A. \& Gennari S.M. 2004. Resistance of Santa Ines, Suffolk and Ile de France sheep to naturally acquired gastrointestinal nematode infections. Vet. Parasitol. 120:91-106.

Antoniassi N.A.B., Pavarini S.P., Ribeiro L.A.O., Silva M.S., Flores E.F. \& Driemeier D. 2010. Alterações clínicas e patológicas em ovinos infectados naturalmente pelo vírus da língua azul no Rio Grande do Sul. Pesq. Vet. Bras. 30(12):719-724.

Araújo M.R., Costa M.C. \& Ecco R. 2009. Ocorrência de pneumonia associada à infecção por Mannheimia haemolytica em ovinos de Minas Gerais. Pesq. Vet. Bras. 29(9):719-724.

Brasil 2009. Manual de Legislação: programas nacionais de saúde animal do Brasil. Departamento de Saúde Animal, Secretaria de Defesa Agropecuária, Ministério da Agricultura, Pecuária e Abastecimento, Brasília. 440p.

Brum K.B., Haraguchi M., Lemos R.A.A., Riet-Correa F. \& Fioravante M.C.S. 2007. Crystal associated cholangiopathy in sheep grazing Brachiaria de- 
cumbens containing the saponin protodioscin. Pesq. Vet. Bras. 27(1):3942

Cal L., Borteiro C., Benech A., Rodas E., Abreu M.N., Cruz J.C. \& González Montaña J.R. 2009. Histological changes of the liver and metabolic correlates in ewes with pregnancy toxemia. Arq. Bras. Med. Vet. Zootec. 61(2):306-312.

Castro M.B., Chardulo L.A.L. \& Szabo M.P.J. 2007. Copper toxicosis in sheep fed dairy cattle ration in São Paulo, Brazil. Arq. Bras. Med. Vet. Zootec. 59(1):246-249.

Castro M.B., Santos Jr H.L., Mustafa V.S., Gracindo C.V., Moscardini A.C.R., Louvandini H., Paludo G.R., Borges J.R.J., Haraguchi M., Ferreira M.B. \& Riet-Correa F. 2009. Brachiaria spp. poisoning in sheep in Brazil: Experimental and epidemiological findings. $8^{\text {th }}$ International Symposium on Poisonous Plants. João Pessoa, Paraíba, Brazil, p.12. (Abstract)

Cruz C., Driemeier D., Pires V.S. \& Schenkel E.P. 2001. Experimentally induced cholangiopathy by dosing sheep with fractionated extracts from Brachiaria decumbens. J. Vet. Diagn. Invest. 13:170-172.

Cunha-Filho L.F.C., Pereira A.B.L. \& Yamamura M.H. 1998. Resistência a anti-helmínticos em ovinos na região de Londrina, Paraná, Brasil. Semina, Ciênc. Agrárias 19:31-37.

Dantas A.F.M., Nobre V.M.T., Riet-Correa F., Tabosa I.M., Júnior G.S. \& Medeiros J.K.D. 2004. Intoxicação crônica espontânea por Crotalaria retusa (Fabaceae) em ovinos na região do semi-árido paraibano, Brasil. Pesq. Vet. Bras. 24(Supl.):18-19.

Driemeier D. 2007. Scrapie, p.475-484. In: Riet-Correa F., Schild A.L., Lemos R.A.A. \& Borges J.R.J. (Eds), Doenças de Ruminantes e Equídeos. Vol.1. Pallotti, Santa Maria, RS.

Driemeier D., Barros S.S., Peixoto P.V., Tokarnia C.H., Döbereiner J. \& Brito M.F. 1998. Estudo histológico, histoquímico e ultra-estrutural de fígados e linfonodos de bovinos com presença de macrófagos espumosos ("foam cells"). Pesq. Vet. Bras. 18(1):29-34.

Headley S.A., Reis A.C.F., Nakagawa T.L.D.R. \& Bracarense A.P.F.R.L. 2008. Intoxicação crônica por cobre em ovinos no norte do Paraná, Brasil: relato de caso. Semina, Ciênc. Agrárias 29(1):179-184.

Guedes K.M.R., Riet-Correa F., Dantas A.F.M., Simões S.V.D., Miranda Neto E.G., Nobre V.M.T. \& Medeiros R.M.T. 2007. Doenças do sistema nervoso central em caprinos e ovinos no semi-árido. Pesq. Vet. Bras. 27(1):2938.

IBGE 2010. Pesquisa da Pecuária Municipal 2010. Instituto Brasileiro de Geografia e Estatística. Disponível em <http://IBGE.gov.br> Acesso em 8 nov. 2011.

Ilha M.R.S., Loretti A.P., Barros S.S. \& Barros C.S.L. 2001. Intoxicação espontânea por Senecio brasiliensis (Asteraceae) em ovinos no Rio Grande do Sul. Pesq. Vet. Bras. 21(3):123-138.

Inaba M. 2000. Red blood cell membrane defects, p.1012-1020. In: Feldman B.F., Joseph G.Z. \& Jain N.C. (Eds), Schalm`s Veterinary Hematology. $5^{\text {th }}$ ed. Lippincot Williams and Wilkins, Toronto, Canada. (Apud Pereira et al. 2009)

Lemos R.A.A. \& Riet-Correa F. 2007. Polioencefalomalacia, p.658-670. In: Riet-Correa F., Schild A.L., Lemos R.A.A. \& Borges J.R.J. (Eds), Doenças de Ruminantes e Equídeos. Vol.2. Pallotti, Santa Maria, RS.

Lemos R.A.A., Ferreira L.C.L., Silva S.M., Nakazato L. \& Salvador S.C. 1996. Fotossensibilização e colangiopatia associada a cristais em ovinos em pastagem com Brachiaria decumbens. Ciência Rural 26(1):109-113.

Lemos R.A.A., Nogueira A.P.A., Souza R.I.C., Santos B.S., Carvalho N.M., Aniz A.C.M. \& Freitas P.C. 2009. Brachiaria spp. poisoning in ruminantes in Mato Grosso do Sul, Brazil. $8^{\text {th }}$ International Symposium on Poisonous Plants. João Pessoa, Paraíba, Brazil, p.98. (Abstract)

Lemos R.A.A., Rangel J.M.R., Osório A.L.A.R., Moraes S.S., Nakazato L., Salvador S.C. \& Martins S. 1997. Avaliações clínicas, patológicas e laboratoriais na intoxicação crônica por cobre em ovinos. Ciênc. Rural 27(3):457-463.

Lima E.F., Riet-Correa F., Tabosa I.M., Dantas A.F.M., Medeiros J.M. \& Júnior G.S. 2005. Polioencefalomalacia em caprinos e ovinos na região semi-árida no Nordeste do Brasil. Pesq. Vet. Bras. 25(1):9-14.

Macêdo J.T.S.A., Riet-Correa F., Dantas A.F.M. \& Simões S.V.D. 2008. Doen- ças da pele em caprinos e ovinos no semi-árido brasileiro. Pesq. Vet. Bras. 28(12):633-642.

Martins H.M. 2011. Scrapie no Estado de Mato Grosso do Sul. Dissertação de Mestrado em Ciência Animal, Faculdade de Medicina Veterinária e Zootecnia, Universidade Federal de Mato Grosso do Sul, Campo Grande, MS. 51p.

Méndez M.C. \& Riet-Correa F. 2007. Intoxicação por cobre, p.62-68. In: Riet-Correa F., Schild A.L., Lemos R.A.A. \& Borges J.R.J. (Eds), Doenças de Ruminantes e Equídeos. Vol.2. Pallotti, Santa Maria, RS.

Mendonça F.S., Camargo L.M., Freitas S.H., Dória R.G.S., Baratella-Evêncio L. \& Evêncio Neto J. 2008. Aspectos clínicos e patológicos de um surto de fotossensibilização hepatógena em ovinos pela ingestão de Brachiaria decumbens (Gramineae) no município de Cuiabá, Mato Grosso. Ciênc. Anim. Bras. 9(4):1034-1041.

Mustafa V.S. 2009. Caracterização da intoxicação natural por Brachiaria spp. em ovinos no Brasil Central. Dissertação de Mestrado em Saúde Animal, Curso de Pós-Graduação em Saúde Animal, Universidade de Brasília, Brasília, DF. 71p.

Nóbrega Júnior J.E., Riet-Correa F., Nóbrega R.S., Medeiros J.M., Vasconcelos J.S., Simões S.V.D. \& Tabosa I.M. 2005. Morte perinatal de cordeiros no semi-árido da Paraíba. Pesq. Vet. Bras. 25(3):171-178.

OIE 2011. Animal Health Information. Disponível em <http://www.oie. int/> Acesso em 20 jan. 2011.

Pereira W.A.B., Hatayde M.R. \& Faria J.L.M. 2009. Microscopia eletrônica de varredura de eritrócitos de ovinos submetidos à intoxicação cúprica acumulativa. Ciênc. Anim. Bras. (Supl.1):348-353.

Radostits O.M., Gay C.C., Blood D.C. \& Hinchcliff K.W. 2007. Veterinary Medicine: A textbook of the diseases of cattle, sheep, pigs, goats and horses. W.B. Saunders, Baltimore. 2065p.

Ribeiro L.A.O., Neto J.A.S.P., Rodrigues N. \& Fallavena L.C.B. 1995. Intoxicação crônica por cobre em ovinos mantidos em pomar de macieiras. Pesq. Vet. Bras. 15(1):15-17.

Ribeiro L.A.O., Rodrigues N.C. \& Smiderle W.A. 2007. Intoxicação crônica por cobre em ovelhas pastoreadas em pomar de videiras adubado com cama aviária. Braz. J. Vet. Res. Anim. Sci. 44(3):208-211.

Riet-Correa B., Castro M.B., Lemos R.A.A., Riet-Correa G., Mustafa V. \& Riet-Correa F. 2011 Brachiaria spp. poisoning of ruminants in Brazil. Pesq. Vet. Bras. 31(3):183-192.

Riet-Correa F. \& Méndez M.C. 2007. Plantas que causam fotossensibilização hepatógena, p.114-122. In: Riet-Correa F., Schild A.L., Lemos R.A.A. \& Borges J.R.J. (Eds), Doenças de Ruminantes e Equídeos. Vol.2. Pallotti, Santa Maria, RS.

Riet-Correa F., Medeiros R.M.T., Pfister J., Schild A.L. \& Dantas A.F.M. 2009. Plants and other substances affecting the liver, p.53-92. In: Ibid. (Eds), Poisonings by plants, mycotoxins and related substances in Brazilian livestock. Pallotti, Santa Maria, RS.

Rissi D.R., Pierezan F., Oliveira Filho J.C., Fighera R.A., Irigoyen L.F., Kommers G.D. \& Barros C.S.L. 2010. Doenças de ovinos da região Central do Rio Grande do Sul: 361 casos. Pesq. Vet. Bras. 30(1):21-28.

Rosa I.V. \& Gomes R.F. 1982. Intoxicação crônica por cobre. Comun. Téc. 14, Embrapa-CNPGC, Campo Grande, MS, p.1-3.

Ruas J.L. \& Berne M.E.A. 2007. Parasitoses por nematódeos gastrintestinais em bovinos e ovinos, p.584-604. In: Riet-Correa F., Schild A.L., Lemos R.A.A. \& Borges J.R.J. (Eds), Doenças de Ruminantes e Equídeos. Vol.1. Pallotti, Santa Maria, RS.

Santos J.C.A., Riet-Correa F., Simões S.V.D. \& Barros C.S.L. 2008. Patogênese, sinais clínicos e patologia das doenças causadas por plantas hepatotóxicas em ruminantes e equinos no Brasil. Pesq. Vet. Bras. 28(1):114.

Saturnino K.C., Mariani T.M., Barbosa-Ferreira M., Brum K.B., Fernandes C.E.S. \& Lemos R.A.A. 2010. Intoxicação experimental por Brachiaria decumbens em ovinos confinados. Pesq. Vet. Bras. 30(3):195-202.

Schild A.L. 2007. Cetose, p.281-286. In: Riet-Correa F., Schild A.L., Lemos R.A.A. \& Borges J.R.J. (Eds), Doenças de Ruminantes e Equídeos. Vol.2. Pallotti, Santa Maria, RS.

Schlumbohm C. \& Harmeyer J. 2008. Twin-pregnancy increases suscepti- 
bility of ewes to hypoglycaemic stress and pregnancy toxaemia. Res. Vet. Sci. 84(2):286-299.

Sczesny-Moraes E.A., Bianchin I., Silva K.F., Catto J.B., Honer M.R. \& Paiva F. 2010. Resistência anti-helmíntica de nematóides gastrintestinais em ovinos, Mato Grosso do Sul. Pesq. Vet. Bras. 30(3):229-236.

Silva N.S., Silveira J.A.S., Campos K.F., Sousa M.G.S., Lopes C.T.A., Oliveira C.M.C., Duarte M.D. \& Barbosa J.D. 2009. Acidose ruminal em ovinos, diagnosticada pela Central de Diagnóstico Veterinário (CEDIVET) da
Universidade Federal do Pará, no período de 2000 a 2008. Anais VIII Congresso Brasileiro de Buiatria, Goiânia, GO, p.191-196.

Urquhart G.M., Armour J., Duncan J.L., Dunn A.M. \& Jennings F.W. 1998. Parasitologia Veterinária. Guanabara Koogan, Rio de Janeiro. 273p.

Viana J.G.A. \& Silveira V.C.P. 2008. Análise econômica da ovinocultura na metade Sul do Rio Grande do Sul, Brasil. Anais XLVI Congresso da Sociedade Brasileira de Economia, Administração e Sociologia Rural, Rio Branco, AC. (Resumo) 